Res Publica. Revista de Historia de las Ideas Políticas ISSN: 1576-4184

http://dx.doi.org/10.5209/RPUB.60853

\title{
El análisis de H. Marcuse en torno a la transición del existencialismo filosófico a existencialismo político en el realismo heroico
}

\author{
Jordi Magnet Colomer*
}

Recibido: 11 de diciembre de 2017 / Aceptado: 15 de junio de 2018

Resumen. Coincidiendo con su entrada como miembro del equipo de trabajo del Institut für Sozialforschung, Herbert Marcuse comienza a desarrollar una teoría materialista de la sociedad alejada del heideggerianismo de su juventud. Durante el período comprendido entre 1933 y 1936, el autor berlinés escribe una serie de artículos cuestionando la deriva política de la filosofía existencial en Alemania. En ellos se confronta con las versiones vulgarizadas de la Lebensphilosophie y de la fenomenología -encabezadas por Heidegger- que proveyeron una suerte de fundamentación filosófica a la "concepción del mundo" (Weltanschauung) del realismo heroico y a las políticas socio-económicas del Estado total-autoritario.

Palabras clave: realismo heroico; existencialismo; Marcuse; Heidegger.

\section{[en] H. Marcuse's Analysis on the Transition from Philosophical Existentialism to Political Existentialism in Heroic Realism}

\begin{abstract}
Since his entry as a member of the Institut für Sozialforschung's work team, Herbert Marcuse begins to develop a materialist theory of society far from his youth Heideggerianism. During the period between 1933 and 1936, the Berlin author writes several essays where he criticizes German existential philosophy's political drift. In these essays, Marcuse confronts Lebensphilosophie and phenomenology's vulgarized versions -headed by Heidegger- which provided a kind of philosophic foundation to the heroic realism's "worldview" (Weltanschauung) and to the totalitarian State's socio-economic policies. Keywords: Heroic Realism; Existentialism; Marcuse; Heidegger.
\end{abstract}

Sumario: 1. Tendencias irracionalistas en la filosofía alemana del siglo XX. 2. El movimiento filosófico de Heidegger desde el reino de la facticidad al reino trascendental. 3. Restituyendo la herencia del idealismo alemán.

Cómo citar: Magnet Colomer, J. (2018). El análisis de H. Marcuse en torno a la transición del existencialismo filosófico a existencialismo político en el realismo heroico, en Res publica 21.2, 321-332.

\footnotetext{
* Universidad de Barcelona jordi.magnet@gmail.com
} 


\section{Tendencias irracionalistas en la filosofía alemana del siglo $\mathrm{XX}$}

Un año después del fallecimiento de Heidegger, Herbert Marcuse colabora con un breve escrito a un volumen colectivo en su memoria. Encabeza significativamente su texto con el epígrafe "Decepción" (Enttäuschung). Por si dicho título todavía dejara alguna duda sobre su contenido, baste agregar por el momento que la decepción experimentada por el autor berlinés lo fue por partida doble. El primer motivo al que hace mención Marcuse para justificar ese sentimiento negativo provocado por la filosofía de Heidegger se le hizo claro ya desde las publicaciones que siguieron a Ser y tiempo (1927), viéndose confirmado gradualmente por la obra posterior de Heidegger. Esa primera decepción estuvo motivada por la constatación de que la concreción filosófica de Heidegger era en realidad una concreción aparente, "que estábamos de nuevo ante una filosofía trascendental (en una escala más amplia), en la que las categorías existenciales perdían su filo, eran neutralizadas y se diluían finalmente en abstracciones cada vez más elevadas"1. No eran, por lo demás, reflexiones que surgieran repentinamente en su etapa de madurez, pues casi cinco décadas antes, siendo todavía alumno de Heidegger, ya sostuvo opiniones similares ${ }^{2}$. El segundo motivo, tanto o más decepcionante, no afloró hasta el año 1933:

Abandoné Friburgo en enero de 1933 . Ni yo ni mis amigos habíamos notado o
sabido nada antes de 1933 de la relación de Heidegger con el nazismo. Sólo más
tarde intentamos establecer una afinidad entre su filosofía y su política. Hoy me
parece indecente minimizar la declaración de Heidegger a favor del régimen de
Hitler como un (breve) paso en falso o un error: creo que un filósofo no se puede
permitir un 'error' tal, sin desautorizar su propia y genuina filosofía.

La tarea de establecer una afinidad entre la filosofía de Heidegger y la política del régimen nacionalsocialista fue abordada muy pronto por Marcuse. En efecto, en sus escritos del período 1933-1936 va a realizar una crítica a la trayectoria irracionalista de la filosofía alemana ${ }^{4}$ que adelanta la exposición que hiciera Lukács en su polémica obra Die Zerstörung der Vernunft (1954). Sin embargo, las ventajas de recurrir a la interpretación marcuseana antes que a la lukacsiana son fácilmente discernibles, incluso en un primer acercamiento: la aproximación de Marcuse está libre del sesgo ideológico y panfletario que empapa todo el estudio de Lukács.

Marcuse acota cuidadosamente el perímetro de sus críticas y su interpretación resulta más dialéctica que la de Lukács. Si el filósofo húngaro decide establecer el inicio de ese itinerario de corte irracionalista en la tendencia romántica del idealismo alemán representada por Schelling, abarcando luego las obras de Kierkegaard,

H. Marcuse, "Enttäuschung", en G. Neske (ed.), Erinnerung an Martin Heidegger, Pfullingen, Neske Verlag, 1977, p. 162.

2 En 1929 Marcuse consideró que la obra de Heidegger se estaba orientando hacia una "metafísica trascendental". Cf. J. M. Romero, "Herbert Marcuse y los orígenes de la Teoría Crítica. Una aproximación", en J.M. Romero, (ed.), H. Marcuse y los origenes de la teoría crítica, Madrid, Plaza y Valdés, p. 19.

H. Marcuse, "Enttäuschung”, en G. Neske (ed.), Erinnerung an Martin Heidegger, op. cit., pp. 162-163.

4 Especialmente, como veremos a continuación, en su artículo de 1933, redactado en francés y publicado póstumamente, sobre la filosofía alemana del período 1871-1933 (“German Philosophy, 1871-1933”), pero también en la reseña de 1933 sobre la obra de Jaspers ("Philosophie des Scheiterns: Karl Jaspers' Werk"), en "La lucha contra el liberalismo en la concepción totalitaria del estado" (1934) y en "El concepto de esencia" (1936). 
Schopenhauer o Husserl, entre otros, la selección de Marcuse es más comedida, pero no por ello menos válida. Se concentra, en cambio, en la última fase del dilatado período abarcado por Lukács, a saber, en las distintas variantes de la filosofía de la existencia (Heidegger, Jaspers) y en las corrientes vulgares de la fenomenología y de la Lebensphilosophie (Scheler, Spengler, etc.). Aunque pudieran prefigurar algunos rasgos de las tendencias irracionalistas posteriores, el cauteloso examen de Marcuse deja fuera de esa trayectoria irracionalista al idealismo alemán, a sus oponentes coetáneos (Schopenhauer y Kierkegaard) y a los fundadores de la escuela fenomenológica (Husserl) y vitalista (Dilthey).

El esmerado análisis del autor berlinés sobre las distintas fases por las cuales ha transitado el concepto de esencia (Wesen) a lo largo de la tradición filosófica occidental, pone de manifiesto un claro propósito de apropiarse dialécticamente de los momentos progresivos del pensamiento filosófico moderno y contemporáneo, al tiempo que un rechazo de las tendencias regresivas que culminarían en el vitalismo y en la filosofía de la existencia. Desde Descartes hasta Husserl, el pensamiento filosófico moderno vació el concepto de esencia de todos aquellos elementos éticos y críticos susceptibles de encauzarse a una transformación material real. En su lugar, el concepto de esencia adoptó una forma trascendental y subjetiva y se vio constreñido a una problemática lógico-epistemológica. El método trascendental de la filosofía de la conciencia burguesa difiere en esto de la doctrina idealista de la esencia de Platón y de la ontología dinámica aristotélica, cuyas resonancias e implicaciones éticas fueron conservadas tanto en la filosofía tomista posterior como en la teoría dialéctica de la esencia de Hegel y en el materialismo histórico. La esencia no es ya, como en los casos anteriores, una potencia en permanente tensión con la realidad de la existencia fáctica, sino que la función que ejerce ahora es meramente cognoscitiva. Con ello se pierde el carácter dinámico y dialéctico de la relación entre esencia (lo que la cosa propiamente es, pero que al no haber sido realizada todavía fácticamente actúa como posibilidad) y existencia (lo que es en su facticidad concreta y empírica) y la concepción del ser verdadero como resultado del devenir. Al renunciar a la idea de una transformación real de las condiciones materiales de existencia, la crítica de la razón de la teoría burguesa pretende compensar la falta de libertad práctica del individuo con la libertad de pensamiento ${ }^{5}$. La hostilidad de la realidad externa, asumida como inalterable, se suple con un ilimitado despliegue del entendimiento y de la razón interna del individuo. Este quietismo, donde el mundo exterior permanece invariable como lo otro extraño y disociado del pensamiento, de la "sustancia" del sujeto, aborta, según Marcuse, la tan anhelada "transición de los conceptos de la razón teórica a los conceptos de la razón práctica"6.

El precio que tuvo que pagar el idealismo de la filosofía trascendental por su confinamiento en la esfera de la razón pura fue la pérdida de contacto con el mundo histórico real. La Escuela neokantiana de Baden, encabezada por Windelband, Lask y Rickert, entendió que este era un coste demasiado elevado y quiso "conceptualizar el mundo histórico y restablecer el contacto perdido con el mundo real"7. Anticipando la diferenciación diltheyana entre ciencias del espíritu (Geisteswissenschaften) y

\footnotetext{
H. Marcuse, “Zum Begriff des Wesens”, en Schriften Vol. 3, Frankfurt am Main, Suhrkamp, p. 52.

Ibidem, p. 54

H. Marcuse, “German Philosophy, 1871-1933”, en R. Wolin y J. Abromeit (ed.), Heideggerian Marxism, Lincoln/London, University of Nebraska Press, 2005, p. 154.
} 
ciencias de la naturaleza (Naturwissenschaften), a Windelband le debemos la distinción entre ciencias ideográficas y ciencias nomotéticas. Si las ciencias nomotéticas se ocupan de indagar las leyes lógicas y generales de procesos causales invariables, las ciencias ideográficas tienen por objeto el estudio de los fenómenos contingentes y cambiantes. A este último grupo pertenecen disciplinas como la sociología o la historia. Sin embargo, cuando los neokantianos de Baden interpretan los eventos históricos lo hacen "en relación a valores de la cultura generales y perpetuos" neokantismo tiene lugar una transformación idealista de la realidad histórica en un sistema de valores eternos que son realizados o impedidos por los diversos acontecimientos históricos. Esta localización trascendental de la historia en el marco de una filosofía de los valores, que tuvo cierta continuidad en la sociología burguesa alemana (M. Weber), se contrapone diametralmente a la teoría materialista de la sociedad.

La entrada en escena de la fenomenología trascendental fue acogida como un revulsivo en la fase de agotamiento del pensamiento filosófico del período liberal. Sin embargo, como último exponente de la teoría de la subjetividad trascendental, Husserl reproduce las mismas aporías que sus antecesores desde Descartes. Según Marcuse, "en el momento en que la teoría de la esencia se convierte en centro de la filosofía de Husserl, su elaboración fuerza a la fenomenología a basarse aún más radicalmente en el apriorismo trascendental"'.

La disociación entre pensamiento racional y realidad espacio-temporal es en Husserl más pronunciada si cabe que en cualquiera de las etapas precedentes de la teoría burguesa, pues al programa de la epoché fenomenológica le es consustancial la separación entre el conocimiento trascendental de la pura subjetividad y el mundo externo $^{10}$. Con la desconexión del ego cogito respecto a la realidad externa, se disipa también el interés de la filosofía por la libertad fáctica del ser humano. Esta tendencia será revertida de modo determinante en los textos del último Husserl sobre la crisis de las ciencias europeas, donde sí es perceptible un claro interés por la libertad -fáctica- del ser humano.

Pero la teoría fenomenológica de la intuición de las esencias es una teoría estática, donde la esencia adopta un carácter descriptivo y epistemológico, sin movimiento tendencial alguno que la oriente hacia la realidad. La esencia concebida como lo que podría ser, en oposición a lo que es y existe de hecho en la realidad, no interesa a la filosofía meramente descriptiva de la fenomenología trascendental. El lema fenomenológico "a las cosas mismas" revela su condición quietista y contemplativa al despojar a las cosas a las que se refiere de su "carácter actual materialmente objetivo" "1. No obstante, mientras la fenomenología trascendental husserliana se nutre todavía del idealismo alemán, la tendencia metafísica-objetiva de la fenomenología, desarrollada por algunos discípulos de Husserl, ya no se vinculará con el idealismo alemán ni con los "momentos progresivos de la conciencia liberal"12.

El soporte filosófico a las políticas sociales y económicas del régimen nacionalsocialista se llevó a cabo suprimiendo las tendencias racionalistas de la fenomenología mediante la subordinación de la razón "a una realidad metafísica esencialmente

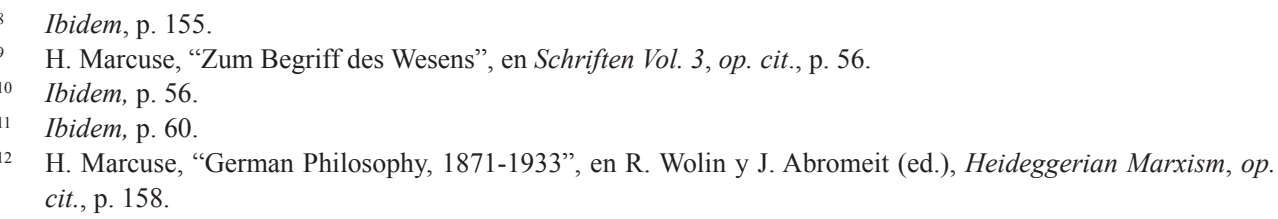


emocional e irracional"13. Lo que empezó como una controversia académica en el ámbito filosófico contra las corrientes materialistas y racionalistas, tuvo luego su correspondiente traducción política en la encarnizada lucha contra la teoría liberal del estado y de la sociedad. El recurso al heroísmo suplantó cualquier justificación racional de la conducta. Como las ingentes dosis de ciega entrega y sacrificio abnegado, necesarias para la estabilización y el mantenimiento del orden existente, resultaban injustificables en términos racionales se apelaba a un pauperismo heroico. Y dado que la concepción de la historia y de la sociedad del realismo heroico-popular era antiracionalista y antimaterialista ${ }^{14}$, las únicas fuentes a las que podía recurrir para justificar esa visión del hombre heroico (unido a las fuerzas de la tierra y de la sangre) eran aquellas escuelas vitalistas donde la vida deviene la principal potencia creadora de la historia. Una vida situada "más allá del bien y del mal" y presentada como "reserva inagotable de fuerzas irracionales" 15 . El decurso histórico social se desprendía así de cualquier encaje en el ámbito económico y material proyectándose como un decurso orgánico-natural.

En esta interpretación naturalista de la sociedad, la naturaleza adquiere dimensiones míticas y prehistóricas, y el pueblo se eleva a representante de una totalidad mistificada. "Al desplazarse la totalidad desde el punto final al inicial, se corta el camino de la crítica teórica y práctica de la sociedad que conduce a esta totalidad" 16 . El equilibrio y la unificación de todas las clases en el todo social tiene como fin "superar la realidad de la lucha de clases" ${ }^{17}$. El pueblo, en tanto que conglomerado en el que ya no resulta posible distinguir entre clases sociales o grupos de intereses, se unifica a través del concepto de raza. Solamente el campesinado, enraizado en la tierra y alejado de la vida de las grandes urbes, encarna las cualidades naturales atribuidas a este pueblo.

El motivo central de la exposición de Marcuse en "La lucha contra el liberalismo en la concepción totalitaria del Estado" (1934) es hacer explícito el vínculo de la teoría social liberal con la teoría totalitaria del estado. Tal como sostiene en este texto, la agresividad política del estado total-autoritario contra el liberalismo es una lucha contra la "concepción del mundo" (Weltanschaunng) que "deja de lado la estructura social fundamental del liberalismo" porque "está plenamente de acuerdo con esta estructura" ${ }^{18}$. El fascismo no desmanteló la estructura social y económica del liberalismo. Los fundamentos económicos del capitalismo liberal industrial fueron simplemente adaptados a la nueva etapa del capitalismo monopolista. La actividad del empresario privado - por ejemplo su capacidad de disponer libremente de los medios privados de

$13 \quad$ Ibidem, p. 158.

14 El carácter regresivo de la concepción del mundo del realismo heroico no pudo conformarse solamente mediante el rechazo del materialismo en cuanto tal, sino que necesitó condenar también cualquier tipo de modernismo en el arte. Durante el Tercer Reich, el arte moderno fue considerado como "degenerado". El sacrificio y el cumplimiento devoto del deber que requería este modelo de reglamentación social, encontró sus tipos ideales en las obras del "arte heroico" (p. ej. Josef Thorak o Arno Breker), donde se ensalzaba el hombre-heroico y se promovían tales valores, ayudando a enraizar el imaginario colectivo y las correspondientes estructuras de la personalidad en los principios de la "sangre y la tierra" (Blut und Boden). Cf. P. Adams, Art of the Third Reich, New York, Abrams, 1992.

15 H. Marcuse, "Der Kampf gegen den Liberalismus in der totalitären Staatsauffassung”, en Schriften Vol. 3., op. cit., p. 8.

16 Ibidem, p. 10.

17 Ibidem, p. 24.

18 Ibidem, p. 13. 
producción-, siguió estando garantizada. De ahí que el adversario político más temido por el liberalismo no fueran los regímenes de Hitler o Mussolini, sino el socialismo marxista.No hay que olvidar que la teoría liberal de la sociedad emplea estrategias de funcionamiento similares a las de la concepción totalitaria del estado. Cuando surgen problemas de armonización entre los intereses particulares y generales, especialmente en las épocas de crisis donde se acentúan las contradicciones sociales y económicas, la teoría liberal recurre a elementos irracionales para poder justificar la estructura y el orden social. "En el racionalismo liberal están preformadas las tendencias que más tarde, con la transformación del capitalismo industrial en capitalismo monopolista, asumirán carácter irracional"19. Por lo demás, tanto en la teoría liberal como en la totalitaria son eternizadas "como «naturales» determinadas relaciones sociales, a fin de conservar el orden existente y protegerlo de toda crítica perturbadora" 20 .

Junto a la preeminencia del todo -en un universalismo abstracto- y al naturalismo organicista, el tercer componente constitutivo del realismo heroico-popular es el existencialismo. En su acepción política, el existencialismo desempeñó un papel determinante en la teoría totalitaria del Estado ${ }^{21}$. La escisión entre la teoría filosófica del idealismo trascendental y la praxis humana, escisión que se repitió con ciertos matices en el neokantismo y en la fenomenología de Husserl, pareció llegar a su fin con la fenomenología de la vida fáctica de Heidegger. Por primera vez, el lugar del sujeto lógico y abstracto del idealismo trascendental fue ocupado por el sujeto actuante en su plena concreción histórica. Sin embargo, Marcuse se apresura a señalar que este "movimiento de la fenomenología al reino de la facticidad fue pronto redirigido hacia el reino trascendental y condujo inmediatamente a la ideología política de la Alemania racista"22. En su opinión, el existencialismo filosófico de Heidegger fue direccionado políticamente, y el pensador alemán pasó a convertirse en uno de los portavoces filosófico del Tercer Reich ${ }^{23}$.

\section{El movimiento filosófico de Heidegger desde el reino de la facticidad al reino trascendental}

La ya temprana inclinación de Heidegger en Ser y tiempo por la construcción de una teoría ontológica del Dasein como misión propiamente filosófica insinuaba el movimiento que tendría lugar en su filosofía desde el reino de la facticidad al reino trascendental. Como el único ente capaz de comprender el ser es el ser humano,

\footnotetext{
Ibidem, p. 17.

Ibidem, p. 29.

21 Otros autores enmarcados en la tradición existencialista o fenomenológica procuraron salvaguardar su independencia, o bien pugnaron por conferir a estas tradiciones una orientación política totalmente distinta. De acuerdo con el razonamiento y la crítica de Marcuse, por "existencialismo político" entendemos aquí exclusivamente la instrumentalización política de la filosofía de Heidegger encauzada a la legitimación de la concepción del mundo del realismo heroico y de la teoría totalitaria del Estado. Una legitimación acentuada por la implicancia activa del autor en el régimen nacionalsocialista, así como con los valores y prejuicios raciales funcionales a ese régimen, tal y como ha puesto de manifiesto - en caso de que quedara todavía alguna duda al respecto- la reciente publicación de los Cuadernos negros de Heidegger del período 1931-38.

22 H. Marcuse, "German Philosophy, 1871-1933”, en R. Wolin y J. Abromeit (ed.), Heideggerian Marxism, op. cit., p. 159.

23 Ibidem, p. 160.
} 
para fundar correctamente una ontología debe analizarse primero al Dasein. Ahora bien, aunque pudiera dar la impresión de que "el ser humano de Heidegger no es la conciencia pura del ego trascendental de Husserl sino el hombre concreto en su facticidad"24, el hombre concreto (Dasein) que Heidegger ansiaba comprender fue distorsionado por él mismo. El proyecto originario de un análisis fenomenológico de la vida fáctica de la existencia concreta se diluyó paulatinamente en una ontología de la existencia humana en general, la cual no difería en aspectos importantes de la metafísica trascendental anterior. La consideración teorética de la esfera material de la existencia histórica del Dasein, que podría haber llevado los análisis ontológicos de la historicidad hacia niveles más altos de concreción, nunca tuvo ninguna relevancia en la obra de Heidegger:

La filosofía -de Heidegger- ha evitado, por buenas razones, examinar más de cerca la facticidad material de la situación histórica del sujeto al que se refiere (...) La filosofía no se preguntó por el tipo de herencia, por la forma de ser del pueblo, por las fuerzas y poderes reales que constituyen la historia. De esta manera renunció a toda posibilidad de poder concebir la facticidad de las situaciones históricas y de valorarlas recíprocamente ${ }^{25}$.

Heidegger remite la auténtica historicidad del Dasein a la "misión" (Sendung) que el pueblo -y no intereses de clase o de grupo-impone al individuo y que éste debe aceptar sin someterla a raciocinio ${ }^{26}$. A menos que rehúse alcanzar una existencia auténtica, al Dasein no le queda otra opción que llevar a cabo esta misión histórica con la máxima celeridad. El carácter decisivo que el cumplimiento de dicha misión adquiere en la realización de la acción resolutiva (Entschlossenheit) del Dasein, hubiese merecido al menos por parte de Heidegger una explicitación algo más específica y concisa, pero en lugar de ello se limitó a ofrecer vagas y difusas referencias desprovistas de cualquier afán de concreción.

El compromiso de la filosofía de la existencia con la situación histórica del $D a$ sein, en claro contraste con la "abstracta carencia de compromiso" ${ }^{27}$ de la filosofía trascendental del período liberal, no es sólo un compromiso abstracto, que ontologiza la historia con el recurso a la historicidad, también es un compromiso a ciegas, donde la situación histórica actual se equipara peligrosamente con la situación histórica verdadera ${ }^{28}$. Puesto que el Dasein no se interroga racionalmente por el tipo de herencia que recibe -un legado gracias al cual puede introducirse de forma resuelta en la situación histórica-, en caso de que la situación actual exija una sumisión total del Dasein para su dominación, no existe en principio criterio valorativo ni racional alguno para oponerse a ello alegando, entre otras razones, que esa situación histórica actual no corresponde a la situación histórica verdadera en la que el Dasein puede realizarse auténticamente.

$24 \quad$ Ibidem, p. 160.

25 H. Marcuse, "Der Kampf gegen den Liberalismus in der totalitären Staatsauffassung”, en Schriften Vol. 3, op. cit., pp. 34-35.

26 Ibidem, p. 37.

27 H. Marcuse, “Philosophie des Scheiterns: Karl Jaspers' Werk”, en H. Saner (ed.), Karl Jaspers in der Diskussion, München, Piper, 1973, p. 131.

28 H. Marcuse, "German Philosophy, 1871-1933”, en R. Wolin y J. Abromeit (ed.), Heideggerian Marxism, op. cit., p. 161 . 
Esta peligrosa equiparación, en la que incurren tanto Heidegger como Jaspers, "autoriza a la existencia en cada situación histórica para su más propia libertad y a partir de cada situación es capaz de existir como ella misma en su "propiedad»" 29 . En consecuencia, la historia se vuelve equivalente y neutral en todas y cada una de sus fases. No creemos que haya una intencionalidad filosófica expresa en neutralizar de este modo la historia, sin embargo es un factor intrínseco a la filosofía existencial de Heidegger y Jaspers desde el momento en que resuelven no incluir la situación material concreta de la existencia fáctica del Dasein en sus respectivos discursos sobre la historicidad ${ }^{30}$.

Suprimiendo la materialidad concreta de la historia del análisis filosófico, queda eliminado también el criterio para poder discernir normativamente si la situación histórica actual responde o no a las auténticas necesidades existenciales y materiales del Dasein. A la manera de ver de un Marcuse ya incorporado en el Institut für Sozialforschung, la realidad histórico-social dada ya no va a ser juzgada como una situación verdadera o falsa según consiga plasmar de un modo más o menos logrado la dimensión ontológica de la esencia del Dasein como historicidad -en el sentido en el que era interpretada la situación histórica concreta por su marxismo heideggerianizado de juventud - sino como una situación histórica en la cual la realización de la libertad y la felicidad terrenal del hombre sean (o no) efectiva y materialmente posibles. Para Marcuse, cuando la situación histórica actual impide la praxis libre del individuo y la organización racional de la sociedad, como requerimientos para dar cumplimiento efectivo a ese telos, entonces el Dasein no debe apropiarse existencialmente de la situación histórica actual sino cancelarla prácticamente. La filosofía de la existencia "no piensa que la existencia humana pueda encontrarse también en situaciones muy «ahistóricas», de las cuales sólo puede salvarse hacia su libertad propia a través de una cancelación práctica de esta situación -y no a través de su apropiación existencial-"'31.Pero aun haciendo uso de un aparato conceptual común, sería un error interpretativo imputar a la filosofía de Jaspers los mismos defectos que a la obra de Heidegger. Así, en el caso de Heidegger, la analítica existencial es sólo una tarea preliminar para llevar a cabo la interpretación del sentido del ser en cuanto problemática ontológica y trascendental. Jaspers, en cambio, se mantiene, de modo perseverante y permanente, en el esfuerzo por aclarar la existencia. Esto ayuda a comprender por qué las categorías empleadas para aprehender la existencia tienen en Heidegger una significación ontológica y en Jaspers ética ${ }^{32}$.

Sin embargo, a juicio de Marcuse, la relevancia de la comunicación como determinación central de la existencia en la filosofía de Jaspers -junto a la libertad y a la historicidad-, es solamente una comunicación entre individuos aislados. Se trata, en definitiva, de una "psicología aristocrática de una mente profunda y delicada" que, no obstante,

29 H. Marcuse, "Philosophie des Scheiterns: Karl Jaspers' Werk", en H. Saner (ed.), Karl Jaspers in der Diskussion, op. cit., p. 131.

30 Tampoco el "existencialismo positivo" de N. Abbagnano, grandilocuentemente presentado como una superación de la comprensión de la existencia sobre el fundamento de la nada (Heidegger) o de la trascendencia (Jaspers), tuvo en consideración alguna la materialidad concreta de la historicidad. Sobre el concepto -desmaterializado- de historicidad en Abbagnano cf. N. Abbagnano, Introducción al existencialismo, México, FCE, 1969, pp. 112-135.

31 H. Marcuse, "Philosophie des Scheiterns: Karl Jaspers' Werk", en H. Saner (ed.), Karl Jaspers in der Diskussion, op. cit., p. 132.

32 Ibidem, p. 130. 
pasa por alto "las fuerzas y penas reales de nuestro tiempo"33. Dos son las observaciones finales que plantea Marcuse en su reseña a la obra Philosophie (1932) de Jaspers. En primer lugar, señala una ambigüedad en el uso de las categorías, que no vendría dada tanto por la insistencia de Jaspers en el proceso de trascender filosófico como por el hecho de haber rehuido conscientemente una confrontación con la historia filosófica de esas categorías. En segundo lugar, arguye que su proyecto filosófico podría haberse enriquecido dirigiéndose a la concreción realmente histórica de la existencia. Por eso la historicidad auténtica es en la filosofía de Jaspers tan abstracta y poco vinculante como en la de Heidegger. Esta ausencia de compromiso vinculante, unida a la abstracción, determina el carácter finalmente inofensivo de la filosofía de la existencia.

La existencia del ser humano que Heidegger y Jaspers analizan no es, pues, la existencia del hombre material y concreto, sino la existencia del hombre aislado y pseudoconcreto, demasiado cercano, pese a las apariencias, al sujeto trascendental del idealismo burgués. Ciertamente, la interpretación del ser en el horizonte del tiempo liberó la ontología de Heidegger de las conceptualizaciones burguesas tradicionales. Pero al mismo tiempo, el desarrollo de la comprensión del ser en el tiempo también sustrajo a la ontología fundamental heideggeriana de la obligatoriedad de constituirse "mediante una explicación conceptual dentro del Logos"34. La "desvalorización del Logos" en la comprensión del ser facilitó la instrumentalización política de esta filosofía en un sentido preciso. La analítica existencial heideggeriana se amoldó perfectamente a la concepción totalitaria del estado y de la sociedad. "Este irracionalismo -escribe Rusconi- se convierte en existencialismo político a un nivel práctico, ofreciendo la plataforma especulativa para el imperialismo económico y político" 35 .Determinados pasajes de Ser y tiempo, en los que Heidegger describe los rasgos fundamentales de la existencia auténtica, hacen patente el modo preciso en que la analítica de la existencia se materializa en un realismo heroico-popular.

La existencia auténtica es realizada a través de la firme voluntad de morir por las propias posibilidades. (...) Las características de la existencia auténtica (resolución, ser-para-la-muerte, aceptación del destino) se separan de cualquier relación con la miseria real y la felicidad del género humano, y de la relación con los fines razonables de la humanidad. Estas características se convierten en las categorías fundamentales del mundo racista ${ }^{36}$.

Las formas de vida (Lebensformen) de la filosofía existencial y del vitalismo menosprecian la facticidad material (no natural) de la existencia. La preocupación por la felicidad terrenal del ser humano deja paso al heroísmo de la pobreza y el sacrificio $^{37}$. Los ideales del humanismo occidental son censurados y su espacio es

33 H. Marcuse, "German Philosophy, 1871-1933", en R. Wolin y J. Abromeit (ed.), Heideggerian Marxism, op. cit., p. 163.

34 H. Marcuse, “German Philosophy, 1871-1933”, en R. Wolin y J. Abromeit (ed.), Heideggerian Marxism, op. cit., p. 161.

35 G. E. Rusconi, Teoría crítica de la sociedad, Barcelona, Martínez Roca, 1969, p. 286.

36 H. Marcuse, "German Philosophy, 1871-1933", en R. Wolin \& J. Abromeit (ed.), Heideggerian Marxism, op. cit., p. 161. Sobre esto véase también F. Olafson, "Heidegger's Politics: an Interview with Herbert Marcuse", en Graduate Faculty Philosophy Journal, n 1/vol.6, 1977, pp. 33.

37 H. Marcuse, "Der Kampf gegen den Liberalismus in der totalitären Staatsauffassung", en Schriften Vol. 3, op. cit., pp. 29-30. 
llenado con la exaltación de actitudes y valores primitivos arraigados en la naturaleza humana. Así, la "comunidad de destino" histórica de Heidegger surge de "datos naturales orgánicos (raza, tierra, sangre), que son, al mismo tiempo, circunstancias «histórico-espirituales»" "38.

Las corrientes vitalistas y existencialistas quisieron independizar la filosofía de los corsés del idealismo trascendental, pero acabaron sometiéndola a las fuerzas económicas y sociales del estado total autoritario. "La destrucción de la razón absoluta y de las categorías del pensamiento burgués no se logró mediante una progresión hacia las estructuras de la historia, sino con un retorno al dominio"39. A decir verdad, la politización del existencialismo filosófico supuso la autoinmolación del propio existencialismo. Con la realización del estado total autoritario, quedó suprimido también el carácter privado de la existencia individual, que operaba como condición de posibilidad para el desarrollo del discurso de la filosofía existencial. En este sentido, Marcuse objeta a Heidegger que este último concibiera el proyecto político del nacionalsocialismo como un modo de redimir al Dasein occidental de los supuestos peligros que lo acechaban (comunismo) cuando, en realidad, el advenimiento del nacionalsocialismo constituía la mayor de las amenazas para el Dasein. No era una forma de redimirlo, sino de suprimirlo ${ }^{40}$.

\section{Restituyendo la herencia del idealismo alemán}

A finales de 1933, durante su etapa como rector de la universidad de Freiburg, Heidegger publicó en la Freiburger Stundentenzeitung impactantes artículos que evidenciaban la forma como el existencialismo político, al poner la filosofía al servicio del estado total autoritario, destruía la herencia del idealismo alemán. Marcuse se acoge a dos escuetas citas, tomadas de esos escritos de Heidegger para la revista estudiantil de la universidad, con el propósito de mostrar el sentido antitético de lo que allí se expone con los principios fundamentales de la filosofía de Kant y de Hegel. Por un lado, si la obra de Kant aparece regulada por la libre autodeterminación del individuo vinculado al deber autónomo, a juicio de Heidegger el Dasein debe vincularse únicamente al caudillo. Por otro lado, el fuerte impulso emancipatorio del idealismo hegeliano, que comprendía el ser gracias a las nociones de razón y de espíritu, es eliminado en Heidegger por tratarse de un ser que ya no tiene otras máximas e ideas que no sean las del Führer ${ }^{41}$.

38 Ibidem, p. 28.

39 H. Marcuse, “German Philosophy, 1871-1933”, en R. Wolin y J. Abromeit (ed.), Heideggerian Marxism, op. cit., p. 162.

40 "Heidegger y Marcuse. Un diálogo epistolar", traducción de Eva de Aguirre, Revista Universidad de Antioquia, Colombia, 2001, n 263, p. 95. Sobre el modo como en el nacionalsocialismo se instituye una "movilización total" de la población -según criterios de racionalidad tecnológica- para el sometimiento de los sujetos a la maquinaria de producción, destrucción y dominación, y el fermento psicológico de la "nueva mentalidad alemana" que surge de ahí, véase también el primer volumen de los Collected Papers de Marcuse, especialmente H. Marcuse, "The New German Mentality", en Technology, War and Fascism, New York, Routledge, 1998.

41 H. Marcuse, "Der Kampf gegen den Liberalismus in der totalitären Staatsauffassung", en Schriften Vol. 3, op. cit., pp. 43-44. Las citas en cuestión son las siguientes: “(...) al caudillo a quien obedece incondicionalmente” (Heidegger, Freiburger Studentenzeitung, 10-11-1933) y "Las reglas de vuestro ser no son las máximas y las ideas. Sólo el caudillo (Führer) es la realidad actual y futura de Alemania y es también su ley” (Heidegger, Freiburger Studentenzeitung, 3-11-1933). 
No obstante, así como Marcuse rechaza tanto el legado trascendental de Kant como la gestión de ese legado por parte del neokantismo, también impugna la teoría ontológico-trascendental del Ser de Hegel y el renacimiento del hegelianismo en la filosofía burguesa (neo-hegelianismo) ${ }^{42}$. Ciertamente, en la teoría materialista de la sociedad la interpretación dialéctica del concepto de esencia procede de la Lógica de $\mathrm{Hegel}^{43}$. Y ello porque la oposición entre esencia y apariencia no es en el idealismo hegeliano epistemológica ni estática, como lo es en la filosofía cartesiana, en el neokantismo o en la fenomenología, sino dialéctica y dinámica. Sin embargo, su teoría de la esencia es igualmente trascendental, pues la relación dialéctica entre esencia y apariencia tiene en Hegel un carácter estrictamente ontológico al ser ubicada en la estructura trascendental del $\mathrm{Ser}^{44}$. Además, el sujeto que toma parte en este proceso es un sujeto meramente cognoscente.

La teoría crítica de la sociedad se beneficia de los avances concretos logrados por la interpretación de la esencia en la obra de Hegel -que, en rigor, no consiste sino en una laboriosa reformulación de la teoría idealista de la esencia platónica y de la ontología aristotélica- y plantea que la relación entre esencia y apariencia, justamente por ser dinámica y dialéctica, posee un carácter antagónico que, en este estado de desarrollo societario, asume la forma de "una desproporción histórica" La tensión entre la esencia como potencialidad y la apariencia como existencia fáctico-empírica, que actúa como verdadero motor de la teoría crítica de la sociedad, no se resuelve con la realización de la esencia en el "puro pensamiento" ni en la "pura intuición" ${ }^{\text {" }}$. La auténtica resolución de la problemática de la esencia debe abordarse en la totalidad del proceso social en un momento histórico determinado. Asimismo, de igual modo que el materialismo histórico enfoca la sociedad como una relación histórica, y nunca como una estructura trascendental del Ser (Hegel) o como una realidad ontológica inmutable, la tensión y la diferencia entre esencia y apariencia es también una "constelación histórica de relaciones sociales"47.

En el materialismo histórico, la preocupación por la esencia del ser humano aparece siempre vinculada a las "tendencias que tienen como objetivo una nueva forma de vida social como la «Idea» de lo que la práctica debe realizar"48. Esta preocupación se inserta, pues, en la transformación práctica del orden existente dirigida a una organización racional de la sociedad. Una nueva organización humana donde haya desaparecido la antítesis entre esencia y apariencia. En este punto, la historicidad del concepto dialéctico de esencia muestra su lejanía respecto a la "concepción fenomenológica de las esencias neutrales" y a la "nivelación neutral de la esencia" del positivismo ${ }^{49}$. En el caso de un Marcuse ya alejado del marxismo ontológico y existencial de su juventud y, por tanto, cada vez más apegado a los planteamientos plenamente materialistas del Institut für Sozialforschung, puede decirse que con la asociación del concepto de esencia "a una praxis humana, dinámica, como había

42 H. Marcuse, “German Philosophy, 1871-1933”, en R. Wolin y J. Abromeit (ed.), Heideggerian Marxism, op. cit., p. 156.

43 H. Marcuse, "Zum Begriff des Wesens", en Schriften Vol. 3, op. cit., p. 66.

44 Ibidem, p. 68.

45 Ibidem, p. 71.

$46 \quad$ Ibidem, p. 72.

47 Ibidem, p. 70.

$48 \quad$ Ibidem, p. 71.

$49 \quad$ Ibidem, p. 70. 
hecho Marx (...) el viejo Marcuse heideggeriano claramente se había desvanecido" 50 . Inscrito en la heterodoxia de la perspectiva histórico-filosófica del marxismo occidental, el materialismo que postula Marcuse no es un determinismo mecanicista entre base económica y superestructura cultural, sino más bien una dialéctica entre forma y contenido. Lo decisivo en el período histórico actual consiste en el hecho de que la economía opera en él como siendo el nivel esencial. Los demás niveles del proceso social son manifestaciones de este estrato fundamental. Pero como los fenómenos relacionados con este proceso se manifiestan a los sujetos en su forma aparencial, la teoría materialista debe trascender la apariencia y el mero análisis de la forma del proceso económico - como producción y reproducción- hasta su contenido esencial: el proceso de realización del capital. Si la falsa conciencia concede una validez supratemporal a la forma histórica del proceso de producción, la conciencia verdadera se dirige más allá de la apariencia inmediata en que las cosas aparecen "hacia otra estructura histórica que está presente como tendencia en la realidad dada" 51 , es decir, hacia la estructura de una sociedad más justa, y tiene en cuenta no sólo el proceso económico de producción y reproducción, sino también el proceso de realización del capital así como el antagonismo entre ambos procesos. Dicho en otros términos, los conceptos dialécticos empleados por la teoría materialista no se limitan a describir las manifestaciones aparenciales del proceso social en la realidad social dada, también buscan explicar el verdadero contenido de tales manifestaciones en la totalidad de la dinámica social.

M. Jay, La imaginación dialéctica, Madrid, Taurus, 1974, p. 137.

51 H. Marcuse, "Zum Begriff des Wesens", en Schriften Vol. 3, op. cit., p. 83. 